\title{
A Wireless SENSOR NeTWORK FOR MONITORING ATMOSPHERIC Aggressiveness IN METALS
}

\author{
Pablo Pancardo ${ }^{1}$, Ebelia del Angel ${ }^{2}$ and Miguel A. Wister ${ }^{1}$ \\ Juarez Autonomous University of Tabasco, Tabasco, Mexico \\ ${ }^{1}$ Informatics and Systems Division \\ ${ }^{2}$ Engineering and Technology Division \\ \{pablo.pancardo, ebelia.delangel, miguel.wister\}@ujat.mx
}

\begin{abstract}
Humid tropical climate favours the existence of a corrosive atmosphere that causes deterioration of metals. This article describes an automated system for monitoring environmental values (temperature and relative humidity) in order to know the time of wetness (TOW), which is key factor in determining the atmospheric aggressiveness which are exposed the metals used, for example, in industrial facilities. System is implemented on a wireless sensor network and the main function of the software developed is to count the time of wetness which is considered the effective time in which metals corrode. System was designed considering the user requirements as the selection of the frequency of measurements, the calculation of TOW and verification of the residual energy of sensor nodes. The results show the effectiveness of the technology used, so that, we can conclude that this type of networks represent a feasible alternative for automated monitoring of corrosion in metals.
\end{abstract}

\section{KEYWORDS}

Wireless Sensor Network, atmospheric aggressiveness, time of wetness, corrosion, humid tropical climate

\section{INTRODUCTION}

The process of atmospheric corrosion of metals and alloys is affected by several climatic parameters such as relative humidity, temperature, wind speed, rainfall, solar radiation, and etcetera. However, one of the most important factors involved is the temperature - relative humidity complex (T-RH-C) in the atmosphere and the wetting time (time of wetness, TOW) on metal surface, during which develops corrosion process. Relative humidity $(\mathrm{RH})$ is the ratio of the amount of water vapor in the air and its saturated value, expressed in percentage, and the temperature is an inverse function of relative humidity. The TOW is the time during which condensation occurs on a surface exposed to the environment, forming a thin film of moisture or water droplets, which acts as an ionic conductor (electrolyte) for the initiation of the corrosion process [1 - 2]. The TOW is determined based on certain critical values of RH and T, when the condensation initiates. According to ISO 9223:92 [3], the TOW can be calculated from the T-RH$\mathrm{C}$, considering those hours of moisture when the $\mathrm{RH} \geq 80 \%$ and $0 \leq \mathrm{T} \leq 25^{\circ} \mathrm{C}$ in clean air, free of contaminants. Our scenario for system deployment in Tabasco, Mexico is part of the humid tropical climate with average annual temperature of $26^{\circ} \mathrm{C}$ and annual mean RH $77 \%$, likewise, with heavy rainfall in certain periods, usually from July to December.

In order to determine atmospheric aggressiveness on air pipes in rural industrial facilities we propose the use of a Wireless Sensor Network (WSN), which is composed of nodes with processing capabilities, communication and measurement of environmental conditions. The nodes 
are physically small and inexpensive; therefore, they have limited resources in terms of bandwidth, power, wireless communication, memory and storage. It's envisioned such networks as an opportunity to make an agile and flexible deployment phase, given the nature of wireless nodes, which allows you to monitor environmental conditions that cause atmospheric aggressiveness of metals [1].

The proposed system is intended to be an early warning of atmospheric aggressiveness which is exposed metals that comprise the air pipes in rural areas free of contaminants. The hypothesis is that the measurements made with the proposed system are as effective as those performed with conventional equipment and more efficient in terms of automation and convenience. Under these facts, the system is suitable to monitor physical parameters that need to be known.

\section{RELATED WORK}

Metal corrosion can be defined as the destructive attack of a metal through interaction with its environment. Corrosion of metals takes place through the action of electrochemical cells. As in all chemical reactions, corrosion reactions occur through an exchange of electrons. In electrochemical reactions, the electrons are produced by a chemical reaction, the oxidation. Although this single mechanism is responsible, the corrosion can take many forms. Some of them are: Microbiological corrosion, which is caused or promoted by microorganisms, usually chemoautotroph. Another type is erosion-corrosion that refers to a corrosion process enhanced by the action of flowing fluids. Fretting corrosion represents other type, which is an attack that is accelerated by the relative motion of contacting surfaces. Despite these types of corrosion we focus on the atmospheric corrosion that varies drastically depending on the geographical location.

There are some related works, although no one of them refers to atmospheric corrosion. In [4], Sridhar and Tormoen use a mobile sensor network to monitor corrosion in pipelines, then, they refer to erosion corrosion. Hedley et.al. [5] developed a sensor network for structural health monitoring. In this case the project focus on detecting and characterizing damage from highvelocity impacts in the skin of aerospace structures that lately causes corrosion, so, they are considering a kind of fretting corrosion. Other research can be found in [6], [7]. Moreover, our proposal is a preventive tool because it allows to anticipate and predict the corrosion levels given environmental conditions, other proposals relate to tools to measure corrosion when it already exists.

\section{SCENARIO CHARACTERISTICS AND CONDITIONS}

Due to the very high annual time of wetness (TOW) values, which provide conditions for higher corrosion rates, even in the presence of low levels of contaminants, compared to different moderate climates. The tropical humid climate of southeastern Mexico and the Gulf of Mexico creates large annual TOW. In rural sites (more than $30 \mathrm{~km}$ from the sea shore), corrosion usually doesn't occur during the day because the air relative humidity is below the critical value $(<80 \%)$ for moisture formation on the metal surface, but many times it is above $80 \%$ during the night, therefore, corrosion occurs. Moreover, it is very important to notice that in tropical humid climates, the TOW coincides with high temperature range. For example, at marine coastal sites, $64-73 \%$ of TOW period occurs when the temperature range is between 25 and $30^{\circ} \mathrm{C}$; in rural sites, $54-64 \%$ of TOW occurs in a lower temperature range $20-25^{\circ} \mathrm{C}$ (each $10^{\circ} \mathrm{C}$ difference corresponds to a tenfold, e.g. by one order of magnitude acceleration of the corrosion process). In our scenario are considered steel pipes coated with zinc, which is a metal used as a corrosion 
protector. However, given the climatic conditions of the stage, these pipes protected with zinc are not exempt of corrosion.

The ability of zinc to galvanically protect steel has made this metal important from an industrial point of view [1-2]. Zinc is relatively resistant to corrosion in neutral environments [8], increasing its localized corrosion degradation in marine-coastal atmospheres due to the presence of airborne particles [9]; it is very sensitive to any change of atmosphere acidity, e.g., SO2 presence.

Although zinc is available in many forms, such as sheet, plate, strip, and pressure die castings, its main use is for corrosion control as a coating on steel and as $\mathrm{Zn}$ anodes for cathodic protection of steel (air pipelines, oil rigs, offshore structures, and bridges).

Particularly, zinc in galvanized hot dip steel is a common metal used for effective corrosion protection of steels (laminated roofs, fences, containers and tubes for water transport, etcetera), very often exposed to outdoor atmospheres with different corrosive aggressiveness.

The period during which a metallic surface is covered by adsorptive and/or liquid film of electrolyte, necessary for initiation and progress of the atmospheric corrosion, is defined as time of wetness (TOW) of the metal surface, according to ISO 9223:92 [10], which can be measured or calculated. Therefore, TOW as a fraction of the total exposure time, determines the duration of the electrochemical corrosion process and denotes explicitly when the mass transport and charge transfer occur during the electrochemical corrosion, and usually TOW does not coincide with all time exposure of metal to atmospheric conditions. Due to this fact, the study of the wetting of metal surfaces in order to understand the process controlling atmospheric corrosion has been gaining attention [11]. The time of wetness of zinc surface, under wet-dry cyclic conditions with different drying periods, is a controlling parameter for the corrosion process kinetic and specifics: the shorter drying period in each cycle leads to higher amount of corrosion products on the metal, because the surface has been under wet conditions for longer periods, necessary for the development of the corrosion process [12]. It is highly recommendable to calculate the distribution of TOW in different temperature ranges, in order to explain metal corrosion process and its rate [11].

\section{SYSTEM OVERVIEW}

Our system proposal follows a simple single hop system layout. It's a single level hierarchical model, where sensor nodes are at the bottom of the hierarchy. All sensor nodes send their sensor readings to the base station, and the base station serves those data to users via the network. Figure 1 shows a sketch of the network architecture.

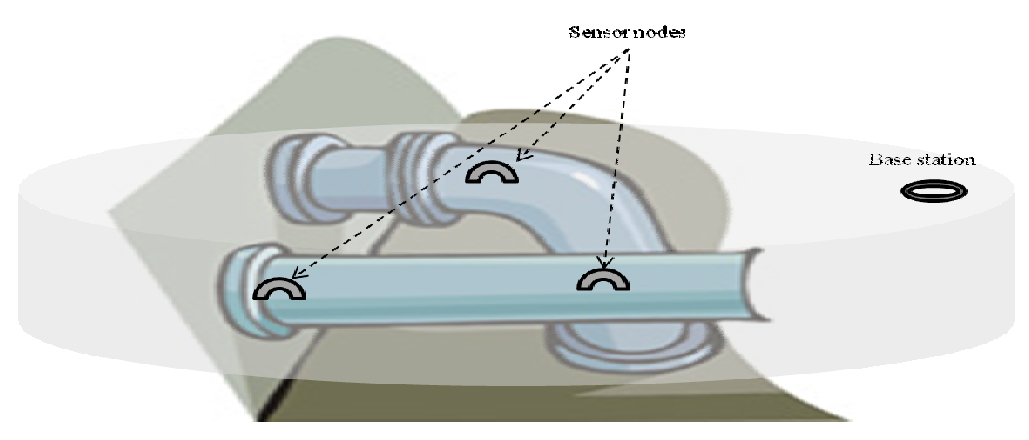

Figure 1. System overview. 


\section{Materials AND Methods}

For the implementation of wireless sensor network, Tmote Sky modules [13] with temperature, humidity and light measurement capabilities have been selected. Tmote Sky platform consists of a wireless board with embedded sensors. It is a board based on the MSP430 microcontroller with a compatible radio chip 802.15.4 standard with a megabyte of external flash memory. Humidity and temperature is measured using the sensor of Sensirion SHT11 [14]. The nodes use two standard AA batteries as a power source. The sensor nodes use TinyOS [15] operating system, which is a reduced version of operating system for sensor nodes. This operating system is built using nesC, a small open language with minimal instruction which has its foundations in the $\mathrm{C}$ language.

Open source software components programmed in nesC [16] were used for acquisition of the data. Data flows of the nodes reach the base station (Personal Computer), by means of a sensor node (base node) inserted into the USB port of the base station. For communication between the base station (PC) and the sensor node placed in its USB port is used net.tinyos.sf.SerialForwarder[15] application, a java-based applet that creates a TCP socket to allow data to be shared with other PC applications. It takes incoming messages from the UART (Universal Asynchronous Receiver-Transmitter) and forwards on an Internet connection so that the PC-based applications can use the data. SerialForwarder also works in another direction: forward requirements packets to the UART and sensor node attached to the computer forwards the message via radio transmission.

In the base node is installed a program called BaseStation (available from the TinyOS components) to process the data that come from nodes and convert them to a text file, which users can access or download this file from the base station and store in their respective computers, where they can analyze.

The data that are coming to the base station can be viewed on the screen of the base station because it uses a modified Java program based on TinyOS Oscilloscope tool. Oscilloscope modifications have been made necessary to meet user requirements and a tool called MIG (Message Interface Generator) has been used to create a Java object-message and thus to get criteria and events of interest user into the system. The modified Java program contains both elements for network management and dynamic configuration options for data acquisition models: event-driven, periodic and on-demand.

Deployed sensor network provides three measurement readings: humidity, temperature and internal voltage. The internal voltage reading is used to determine the amount of battery power currently residing in the sensor node. And therefore, determine the advisability of replacing the batteries when the voltage is less than 2.6, the limit under which the module manufacturer does not guarantee the effectiveness of the readings.

Frequency radio system used by the modules is in the $2.4 \mathrm{GHz}$ band. This band belongs to the radio bands originally reserved internationally for industrial, scientific and medical projects. In general, communications equipment must accept any interference generated by a computer ISM (Industrial, Scientific and Medical). In recent years, these bands have been shared with communications applications fault-tolerant and unlicensed, such as wireless local area networks within the bands of $915 \mathrm{MHz}, 2450 \mathrm{MHz}$ and $5800 \mathrm{MHz}$.

The selected relative humidity sensor has an accuracy of $\pm 2 \%$ and the temperature sensor has an accuracy of $\pm 0.5^{\circ} \mathrm{C}$. Thus, the expected values from the system have ensured a level of confidence. 
For the management of heterogeneous hardware components, has been used to specify data formats independent of the platform for TinyOS using nesC language. This decision allows data to be easily accessed and used independently of the underlying hardware chip. In our study case is considered an industrial setting where there is air pipes embedded in the tropical climate (hot and humid) in Tabasco. Our system consists of nodes that are deployed on the air pipe and capable of measuring ambient temperature and humidity.

Our method was to make measurements of temperature and relative humidity every hour, in the period from $10 \mathrm{pm}$ to $6 \mathrm{am}$ of each day that includes the month of September 2008. Measurements were made at night because it is in those moments when the temperature is more likely to be less than $25^{\circ} \mathrm{C}$ and relative humidity increases. Tabasco State has a mean annual temperature of $26^{\circ} \mathrm{C}$ and an average relative humidity of $80 \%$.

Once we have the number of hours per day the temperature was less or equal to $25^{\circ} \mathrm{C}$ and relative humidity greater than or equal to $80 \%$, and then we have the time of wetness each day, and in turn from TOW month. With previous data we can estimate mass loss of the metal and the corrosion rate according to the formula created for it [17].

Conventional equipments considered for comparison are stationary humidity-temperature thermometer. These kinds of devices can't send information wirelessly and a user has to take measurements reading them directly.

\section{RESULTS}

The developed system to obtain data and manage wireless sensor network has a GUI as shown in Figure 2. The first bottom called "Monitoring" is used to select data acquisition mode, it is a user can choose a periodic sampling (between 3000 and 10,000 ms), on-demand sampling (at any moment) or event-driven sampling (when a condition is met). These options are illustrated in Figure 3 and they are used to obtain values for temperature and relative humidity. As shown in Figure 3, there are two options for WSN management, the first related to node ID change and the second to activate sleep mode in nodes. This last option is employed for energy saving. For example in sunny days or simply during days because in humid tropical climates temperatures minor $25^{\circ} \mathrm{C}$ and relative humidity higher to $80 \%$ usually occurs during nights.

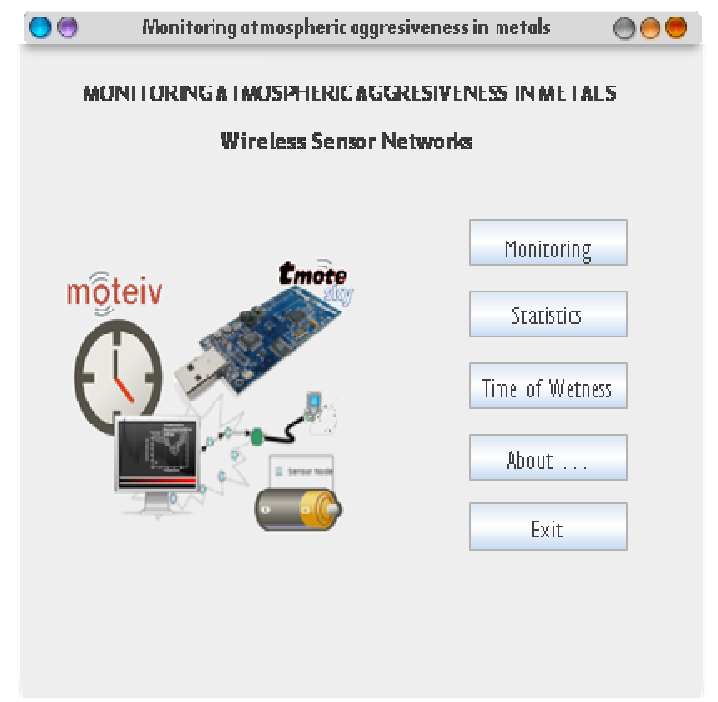

Figure 2. Monitoring atmospheric aggressiveness main panel. 
International Journal of Ad hoc, Sensor \& Ubiquitous Computing (IJASUC) Vol.2, No.4, December 2011

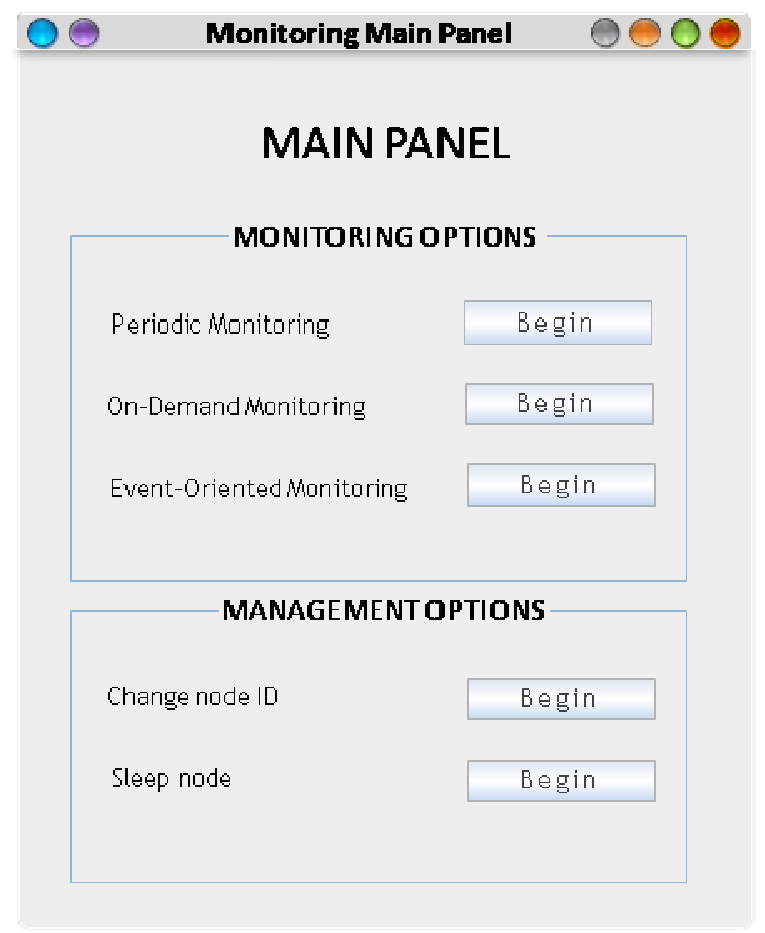

Figure 3. Options for monitoring and management.

In our study case the most convenient data acquisition mode is periodic sampling due it's an automatic unattended monitoring. In this panel users can change sampling rate too. Our system considers an interval between 3000 and 10,000 ms. This panel shows residual energy in volts for each node. Figure 4 shows these options.

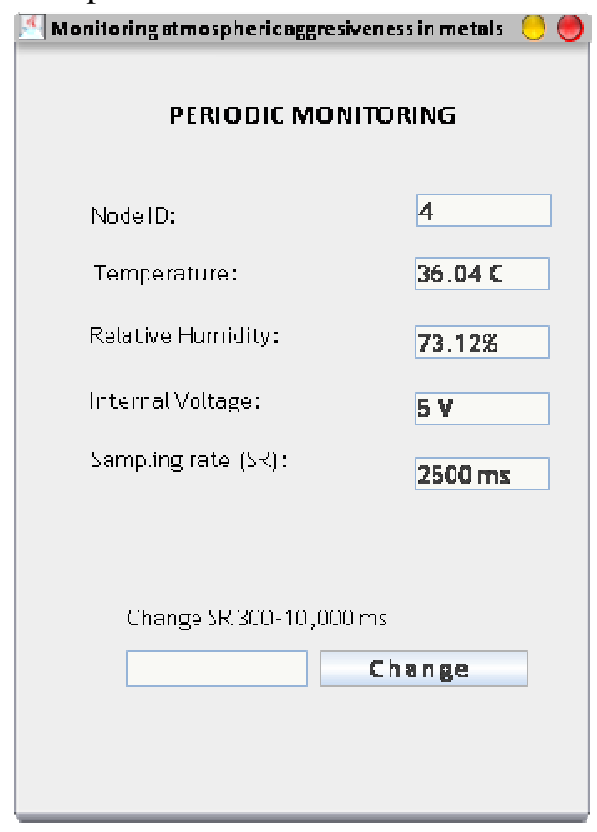

Figure 4. Periodic monitoring and sampling rate selection, including residual energy. 
The system has been deployed in Tabasco, Mexico. This place has warm humid tropical climate and there are many oil installations that use air pipes for the transport of their products (gas, oil and gasoline), therefore the environment is representative of the target system scenarios.

We have monitored the temperature and relative humidity during the month of September 2008. As seen in Table 1 and Table 2, the data obtained by the sensor network are very similar to those obtained using conventional equipment for measuring physical parameters, which do not have wireless communication capabilities, portability problems and cannot be accessed wirelessly to modify the requirements as to the means of acquisition of the data or the frequency in obtaining them, to cite two examples.

For statistical analysis of the data test was used Student's t-distribution, which is appropriate for populations with normal or Gaussian distribution. After that we can infer that the difference between data obtained with conventional equipment and the data obtained with the WSN is negligible.

As mentioned in [18], the rate of zinc corrosion is generally greater than that for copper and less than that for many steels, at least under outdoor atmospheric exposure. It is suggested the following ranges in different environments: rural from 0 to $2-3 \mu \mathrm{m} /$ year, and urban from 2 to 16 $\mu \mathrm{m} / \mathrm{year}$.

Another study of relationship between zinc corrosion and atmospheric parameters is that of Benarie and Lipfert [19]. They stated the corrosion rate as

$$
M=A\left(t_{w} / t\right)^{b}
$$

where $t_{w}$ is the "time of wetness", i.e., the time during which the zinc surface is sufficiently wetted to be covered by an electrolytic solution, and $t$ is the total exposure time. Rather arbitrarily, they define constants in (1) in terms of three chemical parameters at the zinc surface.

$$
\begin{aligned}
& A=4.8+0.53\left(\left\{\mathrm{SO}_{2}\right\}+\left\{\mathrm{Cl}^{--}\right\}\right) \\
& b=1.55-0-142(p H)
\end{aligned}
$$

in which the terms $\left\{\mathrm{SO}_{2}\right\}$ and $\left\{\mathrm{Cl}^{-}\right\}$refer to surface deposition rates and $(\mathrm{pH})$ is the average acidity precipitation.

The mass loss data obtained during the test described in [20] show that can be described with a linear equation:

$$
C=A\left(t_{w}\right)
$$

where $C$ is the loss of mass $\left(\mathrm{g} / \mathrm{m}^{2}\right) ; t_{w}$ - the time of exposure of the samples (TOW), $A$ - the corrosion rate in different environments, depending on climatic parameters and features. In accordance to experiment data obtained in [20], the values of $A$ are approximately $0.0036 \mathrm{~g} / \mathrm{m}^{2} . \mathrm{h}$ for the urban environment and $0.0031 \mathrm{~g} / \mathrm{m}^{2} . \mathrm{h}$ for the rural environment. 
International Journal of Ad hoc, Sensor \& Ubiquitous Computing (IJASUC) Vol.2, No.4, December 2011

Table 1. Media temperature during september 2008

\begin{tabular}{|c|c|c|} 
Hour & WSN sensing & $\begin{array}{c}\text { Measurements with } \\
\text { conventional equipment }\end{array}$ \\
\hline $22: 00: 00$ & $28.3^{\circ} \mathrm{C}$ & $28.5^{\circ} \mathrm{C}$ \\
\hline $23: 00: 00$ & $26.4^{\circ} \mathrm{C}$ & $26.9^{\circ} \mathrm{C}$ \\
\hline $00: 00: 00$ & $25.0^{\circ} \mathrm{C}$ & $25.3^{\circ} \mathrm{C}$ \\
\hline $01: 00: 00$ & $23.7^{\circ} \mathrm{C}$ & $23.6^{\circ} \mathrm{C}$ \\
\hline $02: 00: 00$ & $23.2^{\circ} \mathrm{C}$ & $23.3^{\circ} \mathrm{C}$ \\
\hline $03: 00: 00$ & $22.5^{\circ} \mathrm{C}$ & $22.5^{\circ} \mathrm{C}$ \\
\hline $04: 00: 00$ & $22.6^{\circ} \mathrm{C}$ & $22.5^{\circ} \mathrm{C}$ \\
\hline $05: 00: 00$ & $23.4^{\circ} \mathrm{C}$ & $23.5^{\circ} \mathrm{C}$ \\
\hline $06: 00: 00$ & $24.2^{\circ} \mathrm{C}$ & $24.7^{\circ} \mathrm{C}$ \\
\hline
\end{tabular}

Table 2. Media relative humidity during september 2008

\begin{tabular}{|c|c|c|}
\hline Hour & WSN sensing & $\begin{array}{c}\text { Measurements with } \\
\text { conventional equipment }\end{array}$ \\
\hline $22: 00: 00$ & $72 \%$ & $74 \%$ \\
\hline $23: 00: 00$ & $77 \%$ & $76 \%$ \\
\hline $00: 00: 00$ & $79 \%$ & $80 \%$ \\
\hline $01: 00: 00$ & $83 \%$ & $82 \%$ \\
\hline $02: 00: 00$ & $83 \%$ & $83 \%$ \\
\hline $03: 00: 00$ & $84 \%$ & $83 \%$ \\
\hline $04: 00: 00$ & $81 \%$ & $82 \%$ \\
\hline $05: 00: 00$ & $81 \%$ & $82 \%$ \\
\hline $06: 00: 00$ & $78 \%$ & $79 \%$ \\
\hline
\end{tabular}

Using our system and knowing TOW, corrosion rate and mass loss formulas we can estimated impact of atmospheric aggressiveness in metals, specifically in our scenario, corrosion in zinc galvanized pipes, of course, it can be used to be applied to other metals.

\section{DisCUSSION AND CONCLUSIONS}

Importantly, the proposed technology is very suitable for the scenario of study and the measurement of atmospheric parameters performed with the proposed devices (Tmote) is as effective as those made with conventional equipment (stationary humidity-temperature thermometers), which do not provide the ease of wireless communication devices. Thus it is found that the results are good, although low-cost technology (Tmote) is commonly used for academic purposes. Specialized conditions of moist warm climate of Tabasco, make the equipment used are sufficient to determine with much certainty the level of aggressiveness 
atmosphere to which metals are exposed. The devices used and software developed provide information to take control of wetting times which mean the effective time when metals corrode.

The proposed system represents an opportunity to automate monitoring of atmospheric aggressiveness, such as corrosion of metals in the warm humid tropical climates. Sensor nodes are capable of efficiently measuring temperature and relative humidity environment, so it is enough to know the time of wetness that a metal is exposed and therefore estimate the rate of corrosion and mass loss.

The wireless sensor network used allows measurement data are transmitted wirelessly to the base stations, where data are accumulated and made the process of calculating the time of wetness when temperatures are below $25^{\circ} \mathrm{C}$ and relative humidity is above $80 \%$. A future work considered is the construction of a tool to schedule the preventive corrosive maintenance of metals, based on the corrosion rates and mass loss estimated from measurements made by the wireless sensor network.

\section{ACKNOWLEDGEMENTS}

This work has been funded by UJAT-POA 20080104 project.

\section{REFERENCES}

[1] C.J. Slunder, W.K. Boyd, Zinc: Its Corrosion Resistance, second ed., Int. Lead Zinc Research Org. Int., New York, 1983.

[2] X.G. Zhang, Corrosion and Electrochemistry of Zinc, Plenum, 1996.

[3] I. F. Akyildiz, W. Su, Y. Sankarasubramaniam, E. Cayirci. "A Survey on Sensor Networks”, IEEE Communications Magazine, Vol. 40-8, pp. 102-116, 2002.

[4] N. Sridhar, G. Tormoen. "Development and Application of Mobile Sensor Network to Monitor Corrosion in Pipelines”, CORROSION 2006, March 12 - 16, 2006 , San Diego, Ca.

[5] M. Hedley, N. Hoschke, M. Johnson, C. Lewis, A. Murdoch, D. Price, M. Prokopenko, A. Scott, P. Wang, and A. Farmer. "Sensor Network for Structural Health Monitoring”, International Conference on Intelligent Sensors, Sensor Networks and Information Processing, Melbourne, Australia, December, 2004.

[6] F. Ayello, D. Hill, S. Marion, N. Sridhar. "Integrated Sensor Networks for Corrosion under Insulation: Monitoring, Cost Reduction, and Life Extension Strategies”, NACE Conference 2011.

[7] J. Demo, A. Steiner, F. Friedersdorf, M. Putic, "Development of a Wireless Miniaturized Smart Sensor Network for Aircraft Corrosion Monitoring”, Aerospace Conference, 2010 IEEE.

[8] M. Pourbaix, Atlas of Electrochemical Equilibria in Aqueous Solutions, NACECebelcor, Houston, 1974.

[9] A.K. Neufeld, I.S. Cole, A.M. Bond, S.A. Furman, Corros. Sci. 44 (2002) 555-572.

[10] ISO 9223:92 Corrosion of metals and alloys, Corrosivity of atmospheres, Classification, ISO Int., Geneva, 1992.

[11] L. Veleva, R. Kane, Atmospheric corrosion, in: S.D. Cramer et al. (Eds.), Corrosion, Fundamentals, Testing and Applications, ASM Handbook Series, vol. 13A, ASM Int., OH, 2003, pp. 196-209.

[12] A.P. Yadav, A. Nishikata, T. Tsuru, Corros. Sci. 46 (2004) 169-181.

[13] Tmote Sky. Available in Web: www.snm.ethz.ch/pub/uploads/Projects/tmote_sky_datasheet.pdf

[14] Sensirion SHT11 datasheet. Available in Web. www.sensirion.com

[15] TinyOS operating system. Available in Web: http://www.tinyos.net/ 
International Journal of Ad hoc, Sensor \& Ubiquitous Computing (IJASUC) Vol.2, No.4, December 2011

[16] nesC: A Programming Language for Deeply Networked Systems. Available in Web: http://nescc.sourceforge.net/

[17] L. Veleva, M. Acosta, E. Meraz, Corrosion Science 51 (2009) 2055-2062.

[18] E. Mattsson. Chemtec 15, 234 (1985).

[19] M. Benarie, F.L. Lipfert, Atmos. Environ. 20 (1986) 1947-1958.

[20] E. Del Angel, L. Veleva, M. Acosta. (2006): Evaluación de la corrosión atmosférica del acero galvanizado en el clima tropical húmedo del Golfo de México. Congreso Latinoamericano de Corrosión, Fortaleza, Brasil, 21-26 de mayo.

\section{Authors}

Pablo Pancardo got a Master Science degree in Distributed Systems from ITESM (Mexico); he is a PhD Candidate in Telematic Systems Engineering from Technical University of Madrid (Spain). Currently he works as a teacher in Autonomous Juarez University of Tabasco (Mexico). His areas of interest are wireless ad hoc sensor networks, mobile and ubiquitous computing, and middleware for heterogeneous devices.

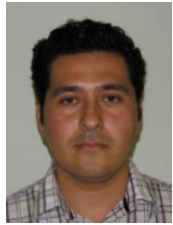

Ebelia del Angel is a Researcher at Autonomous Juarez University of Tabasco. She got a Phd in Corrosion from Campeche University (Mexico). Her interest area is atmospheric Corrosion, sp ecifically about Runoff-Induced Atmospheric Corrosion of Zinc.

Miguel A. Wister is currently a professor in the Information Technology and Systems Division at the Autonomous Juarez University of Tabasco (UJAT). His research interests are in wireless communications and networking, mobile Ad hoc networks (MANET), and service discovery and routing protocols in MANET. Professor Wister received his Ph.D. in Information Technology and Communications Engineering from the University of Murcia, Spain, in 2008; he also received his M.Sc. degree in Informatics Technology from the Monterrey Institute of Technology and Higher

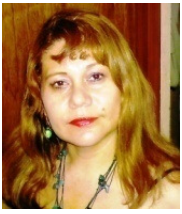
Education (ITESM), Mexico, in June 1997. 